\title{
Cardiologist and cardiac surgeon view on decision-making in prosthetic aortic valve selection: does profession matter?
}

\author{
N. M. Korteland • J. Kluin • R. J. M. Klautz • \\ J. W. Roos-Hesselink • M. I. M. Versteegh • \\ A. J. J. C. Bogers • J. J. M. Takkenberg
}

Published online: 12 June 2014

(C) The Author(s) 2014. This article is published with open access at Springerlink.com

\begin{abstract}
Aims Assess and compare among Dutch cardiothoracic surgeons and cardiologists: opinion on (1) patient involvement, (2) conveying risk in aortic valve selection, and (3) aortic valve preferences.

Methods and results A survey among 117 cardiothoracic surgeons and cardiologists was conducted. Group responses were compared using the Mann-Whitney U test. Most respondents agreed that patients should be involved in decisionmaking, with surgeons leaning more toward patient involvement (always: $83 \%$ versus $50 \%$ respectively; $p<0.01$ ) than cardiologists. Most respondents found that ideally doctors and patients should decide together, with cardiologists leaning more toward taking the lead compared with surgeons $(p<0.01)$.

Major risks of the therapeutic options were usually discussed with patients, and less common complications to a lesser extent. A wide variation in valve preference was noted with cardiologists leaning more toward mechanical prostheses, while surgeons more often preferred bioprostheses $(p<0.05)$.

Conclusion Patient involvement and conveying risk in aortic valve selection is considered important by cardiologists and
\end{abstract}

N. M. Korteland • A. J. J. C. Bogers · J. J. M. Takkenberg $(\triangle)$

Department of Cardiothoracic Surgery, Erasmus MC, Bd563, PO

Box 2040, 3000CA Rotterdam, the Netherlands

e-mail: j.j.m.takkenberg@erasmusmc.nl

J. W. Roos-Hesselink

Department of Cardiology, Erasmus MC, Rotterdam, the Netherlands

J. Kluin

Department of Cardiothoracic Surgery, UMC Utrecht, Utrecht, the

Netherlands

R. J. M. Klautz • M. I. M. Versteegh

Department of Cardiothoracic Surgery, LUMC, Leiden, the

Netherlands cardiothoracic surgeons. The medical profession influences attitude with regard to aortic valve selection and patient involvement, and preference for a valve substitute. The variation in valve preference suggests that in most patients both valve types are suitable and aortic valve selection may benefit from evidence-based informed shared decision-making.

Keywords Shared decision-making · Aortic valve replacement $\cdot$ Aortic valve prostheses

\section{Introduction}

For most patients with severe aortic valve disease, aortic valve replacement is the treatment of choice. For the majority of patients two options exist: mechanical or bioprosthetic aortic valve replacement [1]. The decision for a particular prosthetic valve type is ideally driven by scientific evidence on patient outcome after implantation with different valve substitutes, the patient's clinical state and circumstances, and informed patient preferences. Each valve type has specific advantages and disadvantages. Mechanical valves are designed to last a lifetime, so a lower re-operation hazard can be anticipated, compared with bioprosthetic valves. However, mechanical valves carry an increased thrombotic risk and therefore require lifelong anticoagulation [2]. Clinical characteristics such as age, anticipated life expectancy, indication/contraindication for anticoagulation, and comorbidities play an important role in the decision-making process [3]. Given the different nature of the pros and cons of different prosthetic valves, informed patient preferences deserve consideration in the decisionmaking. Shared decision-making is receiving more and more attention in healthcare [4]. Using shared decision-making, patients are stimulated to think about their treatment, about treatment options and associated benefits and harm so they can place these in their own personal context and discuss their 
preferences with the physician and then decide with their physician what treatment option is best for them [5].

The 2012 ESC/EACTS Valvular Heart Disease Guidelines state that a mechanical or bioprosthetic valve should be recommended according to the desire of the informed patient [2]. But how do we inform the patient? And how do we assess patient preferences? The opinion of Dutch cardiothoracic surgeons and cardiologists on shared decision-making is as yet undefined [6]. To investigate shared decision-making in daily cardiovascular practice, we performed this study. The purpose of this study was to assess the expert opinion of the cardiothoracic surgeon and cardiologist on patient involvement and conveying risk in aortic valve selection, and to assess prosthetic aortic valve preferences of cardiac surgeons and cardiologists.

\section{Methods}

A survey was administered to cardiothoracic surgeons (in training) during the semi-annual meeting of the Netherlands Association for Cardiothoracic Surgery (November 2011) and distributed among cardiothoracic surgeons in several institutions (2012). The same survey was administered to cardiologists (in training) attending the semi-annual meeting of the Netherlands Society of Cardiology (May 2012) and distributed among cardiologists in several institutions (2012).

The questionnaire consisted of five general questions: physician age, speciality (surgeon (in training), cardiologist (in training)), hospital, number of years in practice, and annual number of aortic valve replacements in their institution. The physicians were asked five questions to assess their opinion on involvement of patients in decision-making using a Control Preference scale [7, 8] and 5-point Likert scales [6,9]. Physician perspective on discussing risks and benefits of different prosthetic valve types was assessed by rating how often each complication will be discussed using 5-point Likert scales ranging from never to always. Physician opinion on choice of treatment strategies was assessed by six hypothetical cases in which the physician rated the likelihood of choosing a particular prosthetic valve type using 7-point Likert scales ranging from 1 (definitely mechanical valve) to 7 (definitely bioprosthetic valve). For a detailed description of the questionnaire, see Appendix.

\section{Statistical methods}

Continuous variables are displayed as mean, standard deviation and range, discrete variables as counts or proportions. Comparison of group characteristics was done using the unpaired t-test. Group responses are displayed as median, interquartile range, and total range. To compare group responses between surgeons and cardiologists and influence of physician age and cardiac surgery program in the respondent's institution on survey response, the Mann-Whitney U-test was used at a probability value of 0.05 . All tests were two-sided, and a p-value of 0.05 or less was considered statistically significant. All statistical analyses were performed using IBM-SPSS 20 (IBM Corp., Armonk, NY).

\section{Results}

A total of 117 Dutch medical specialists from 38 different institutions participated. Mean age was $47 \pm 10$ years (range 26-67), mean clinical experience $14 \pm 9$ years (range 0-36). Fifty-four cardiothoracic surgeons (11 in training) represent $38 \%$ of the Dutch cardiothoracic surgeon population, 63 cardiologists (7 in training) represent $6 \%$ of the Dutch cardiologist population. There were no differences in age and clinical experience between the cardiothoracic surgeons and cardiologists.

Physician view on patient participation in decision-making

Figure 1 displays physician preferences for patient involvement and the conveying risk. Figure 2 displays physician preferences for final decision-making in prosthetic aortic valve choice. Subgroup analysis revealed that physicians above the age of 50 more often lean toward patient involvement in decision-making than physicians under age 50. Physicians working in a centre with cardiac surgery were more inclined to decide together with the patient, while physicians working in a centre without a cardiac surgery program more often preferred to take the lead in decision-making.

\section{Physician view on conveying risk and benefit}

Figures 3 and 4 summarise physician responses regarding conveying risk and benefit to patients about mechanical valves (Fig. 3) and bioprosthetic valves (Fig. 4).

There were no differences between surgeons and cardiologists regarding conveying risk and benefit to patients. Physicians under the age of 50 more often informed patients regarding anticoagulation risks than physicians older than age 50. Physicians working in a centre with cardiac surgery more often informed patients about the risks and benefits of a mechanical valve compared with those working in a centre without a cardiac surgery program.

Physician prosthetic valve preferences

The results of the answers to the six hypothetical patient cases are illustrated in the box-and-whisker plot in Fig. 5. Physicians above the age of 50 were leaning more toward mechanical valves compared with physicians under age 50 . The presence of a cardiac surgery program in the respondent's institution was not associated with prosthetic valve preferences in any of the six hypothetical cases. 
Fig. 1 Cardiologist (C) and surgeon (S) preference for patient involvement and risk conveyance in aortic valve selection. Total $n=$ 117 , cardiologists $=63$ and surgeons $=54$. Difference between groups: $* p<0.01$. Pts $=$ patients. $Q o L=$ quality of life

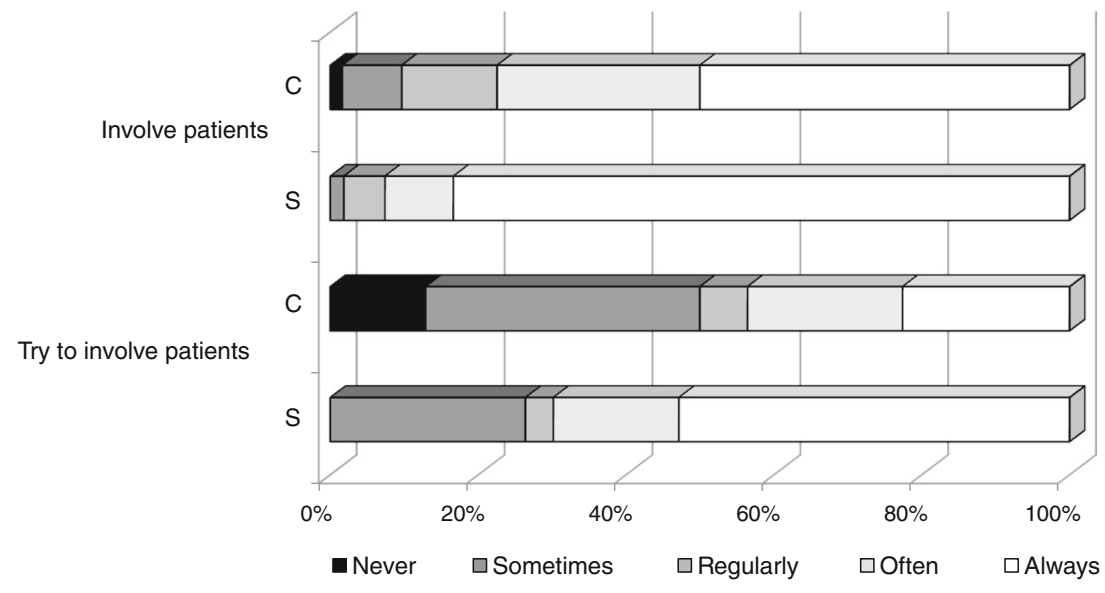

current clinical practice. Current practice in one hospital could, for example, be that the surgeons are mainly discussing the choice for a certain valve type with the patients, while in another clinic cardiologists do so, or both specialities together. Although the $2012 \mathrm{ESC} /$ EACTS Valvular Heart Disease Guidelines state that a prosthetic valve should be recommended according to the desire of the informed patient [1], the way Dutch hospitals are following these guidelines probably differs a lot. The Netherlands Association for Cardiothoracic Surgery and the Netherlands Society of Cardiology should make efforts to achieve a more uniform application of the guidelines in Dutch cardiovascular practice.

Most respondents thought that the physician can often decide for patients how risks and benefits should be weighed, and how quality of life should be weighed against life expectancy. It is, however, doubtful that a physician is actually good at assessing patient preferences in the context of prosthetic aortic valve selection. Physician perception of patient preferences in cardiovascular practice has not yet been investigated, but previous studies in the fields of vascular surgery and colorectal cancer screening have shown that physician perception of patient preferences may differ considerably from actual patient preferences
Fig. 2 Physician preference for final decision in prosthetic aortic valve choice. Total $n=117$, cardiologists $=63$ and surgeons $=$ 54. Difference between cardiologists and surgeons: $p<0.01$

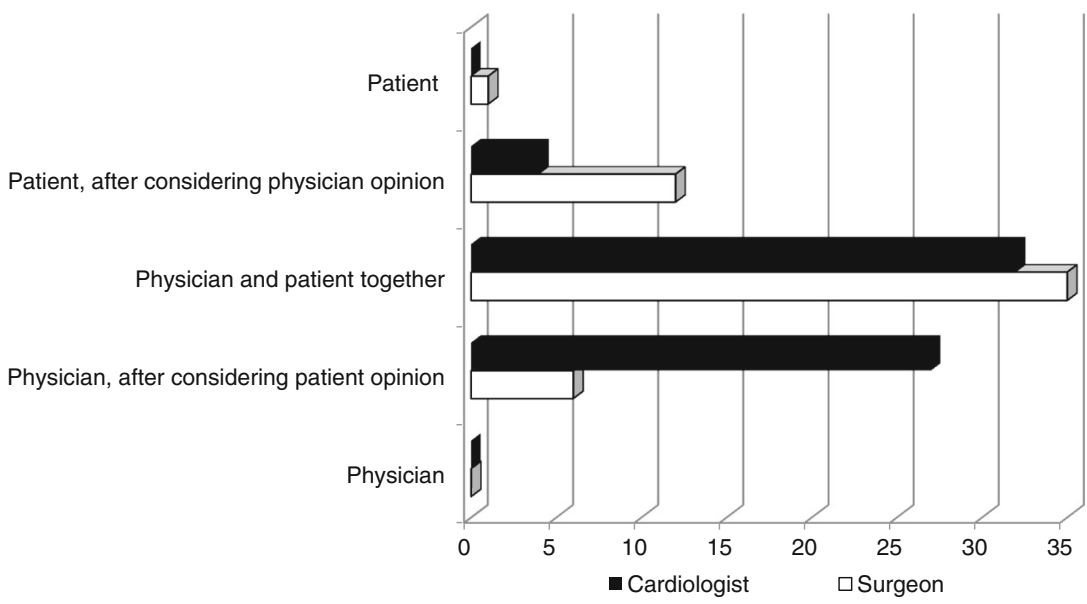


Fig. 3 Physician responses regarding risk and benefit conveyance to patients about mechanical valves. Total $n=117$

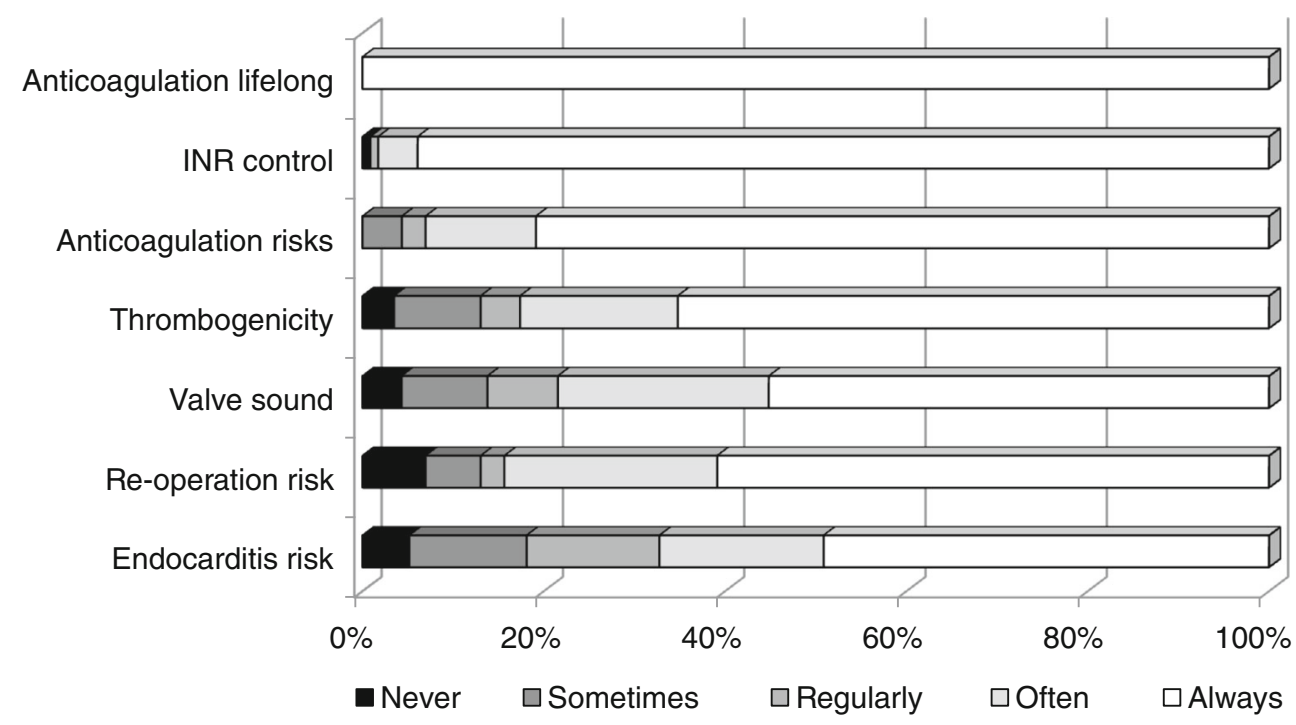

$[11,12]$. In fact, it was shown that although physicians usually think that they can adequately assess patient preferences, reality shows that they cannot do this. This is regardless of the clinical experience they have: from first-year residents to senior registrars, this deficit persists [13]. Because physicians have a major influence on patient decision-making, it is important for the physician to realise that their preferences may not be the preferences of the patient.

Patients who require aortic valve replacement need to be informed about the risks and benefits associated with the different prosthetic valve types in order to be able to participate in decision-making. The current study shows that in Dutch cardiovascular clinical practice major risks of the different therapeutic options are usually discussed with patients, and less common complications to a lesser extent. The observation that younger physicians more often report informing the patients regarding anticoagulation risks and that physicians working in an institution with a cardiac surgery program more often report informing patients about risks and benefits regarding a mechanical prosthesis, reflects the fact that evaluation of the risks and benefits is a complex process. This complexity is due to uncertainty about the various outcomes, difficulty to evaluate future events and the fact that most patients are unfamiliar with the medical consequences of their decisions [1].

The observation that both patient involvement and information provision to the patient are more common in institutions with a cardiac surgery program may be associated with the fact that these institutions have formal heart teams in which the cardiologists and surgeons discuss prosthetic valve selection.

To make patients more familiar with their treatment options it is important to inform patients, in a way that they can understand, about the benefits and risks associated with the different valve
Fig. 4 Physician responses regarding risk and benefit conveyance to patients about bioprosthetic valves. Total $n=117$

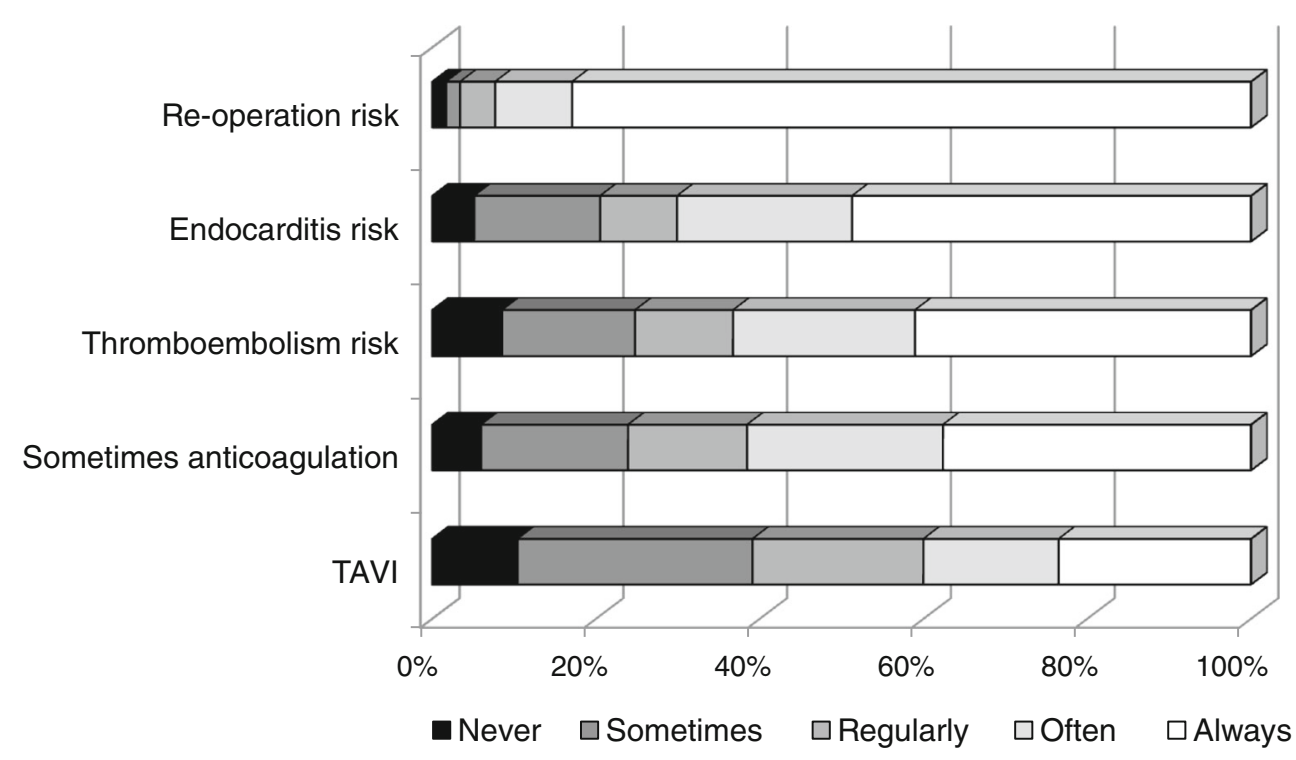




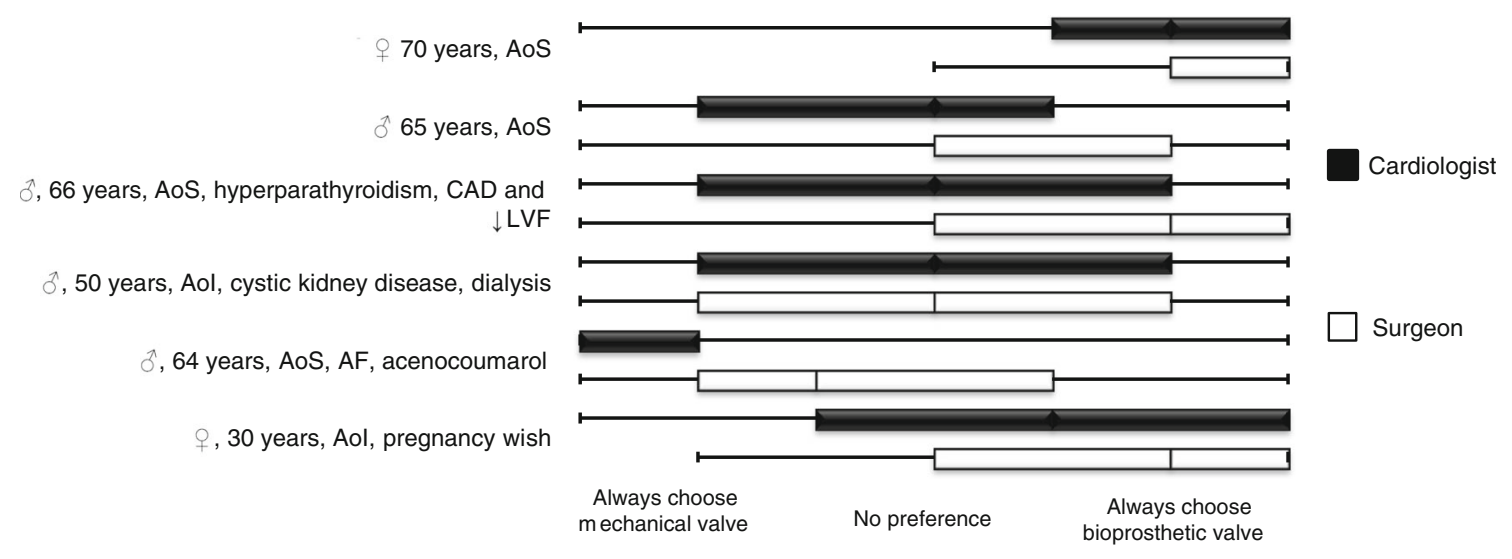

Fig. 5 Physician preferences for a prosthetic valve type in 6 cases. The box contains $50 \%$ of the physician preferences. The vertical line in the box represents the median, and the whiskers illustrate the minimum and

maximum value. Total $n=117$, cardiologists $=63$ and surgeons $=54$. Difference between groups: ${ }^{*} p<0.05$

types. Well-informed patients are an essential requirement for successful shared decision-making. Only then can patients decide what is best for them and this will result in an optimisation of valve selection and an improved quality of life [14]. Of course, patients differ in their information needs. Some patients want to know every detail of their treatment, while other patients do not want to be involved at all. Furthermore, the educational level of the patient plays an important role in shared decision-making. It is known that incapacity to understand the process of medical decision-making is common [15]. Despite these differences in information needs and educational level, it is important that physicians should at least try to involve the patient. In some patients, however, this will require a lot of time and effort from the treating physician. Patient decision aids may be particularly useful in this setting. A decision aid will provide the patient with information about the disease, treatment options and risks and benefits that are associated with the different treatment options. Additionally, a decision aid helps the patient to place the provided information in his or her own context, considering the values and expectations of the patient. It is known that decision aids improve patient knowledge and lower decisional conflict without raising anxiety levels [16]. Only when patients are fully informed about their treatment options can they participate in the decisionmaking process and clarify their preferences to the physician. Although not all patients are willing to participate in decisionmaking, it is known that most patients do want to be informed [17] . Even patients who initially do not want to be involved in decision-making, do want to be involved once they are well informed $[10,18]$.

An important finding of the current study is the observed wide variation in physician preferences for a particular valve substitute and the association between medical speciality and prosthetic valve preferences. It may be that this variation is caused by differences in clinical practice setting, although we could not detect a difference between practices with or without an onsite cardiac surgery program. It may also be that physicians feel that in most patients both valve types are suitable. This is supported by the observation that in current practice there appears to be no difference in survival for adult patients with a mechanical or a bioprosthesis [19-22]. If the type of implanted prosthesis is not associated with patient survival, then the choice for a particular aortic valve prosthesis is mainly driven by valve-related event occurrence. Given the completely different nature of valve-related events between mechanical and bioprostheses, and subjective aspects of choosing between the hazards of bleeding due to anticoagulation (mechanical prostheses) and the hazards of re-operation (biological prostheses), informed patient preferences become very important.

In conclusion, this survey among Dutch cardiothoracic surgeons and cardiologists provides important information on current clinical decision-making regarding prosthetic aortic valve selection. Dutch cardiovascular professionals are of the opinion that prosthetic aortic valve selection should be done with the patient, and they usually convey most risks and benefits of the different options to the patient. Medical speciality influences both physician attitude with regard to prosthetic aortic valve selection and patient involvement, and preference for a particular valve substitute. The observed wide variation in prosthetic aortic valve preferences among Dutch cardiothoracic surgeons and cardiologists suggests that for most patients both mechanical and bioprosthetic valves are suitable, and that formal implementation of the concept of shared decision-making including the use of patient decision aids may be helpful for physicians and patients to improve patient information and patient participation in decisionmaking.

Conflict of interest None declared.

Funding None. 


\section{Appendix}

1. Do you think patients should be involved in choosing an aortic valve?

Never Sometimes Regularly Often Always I don't know

2. If a patient doesn't want to be involved in choosing an aortic valve, do you think that physicians should try to involve the patient in the decision?
Never
Sometimes
Regularly
Often
Always
I don't know

3. The final decision in prosthetic aortic valve choice should be made by:

$\circ$ The patient

○ The patient, after considering physician opinion

$\circ$ The patient and the physician together

$\circ \quad$ The physician, after considering patient opinion

$\circ$ The physician

4. To choose a prosthetic aortic valve, the advantages and disadvantages of different prosthetic aortic valve types are taken into consideration. Do you think physicians can decide for patients how risks and benefits should be weighed?

Never Sometimes Regularly Often Always I don't know

5. Do you think that all disadvantages of a prosthetic aortic valve should be discussed with the patient (even if there is a small chance)?
Never
Sometimes
Regularly
Often
Always
I don't know

6. How often do you inform the patient about the following issues regarding a mechanical valve?

\begin{tabular}{|c|c|c|c|c|c|}
\hline \multicolumn{6}{|c|}{$\circ \quad$ Anticoagulation lifelong } \\
\hline Never & Sometimes & Regularly & Often & Always & I don't know \\
\hline \multicolumn{6}{|c|}{ ○ INR control } \\
\hline Never & Sometimes & Regularly & Often & Always & I don't know \\
\hline \multicolumn{6}{|c|}{$\circ$ Anticoagulation risks } \\
\hline Never & Sometimes & Regularly & Often & Always & I don't know \\
\hline \multicolumn{6}{|c|}{ ○ Thrombogenicity } \\
\hline Never & Sometimes & Regularly & Often & Always & I don't know \\
\hline \multicolumn{6}{|c|}{$\circ \quad$ Valve sound } \\
\hline Never & Sometimes & Regularly & Often & Always & I don't know \\
\hline \multicolumn{6}{|c|}{ ○ Re-operation risk } \\
\hline Never & Sometimes & Regularly & Often & Always & I don't know \\
\hline \multicolumn{6}{|c|}{$\circ \quad$ Endocarditis risk } \\
\hline Never & Sometimes & Regularly & Often & Always & I don't know \\
\hline
\end{tabular}

How often do you inform the patient about the following issues regarding a bioprosthetic valve?

- Re-operation risk

Never Sometimes Regularly Often Always I don't know 
○ Endocarditis risk

Never Sometimes Regularly Often Always I don't know

○ Thromboembolism risk

\begin{tabular}{|c|c|c|c|c|c|}
\hline Never & Sometimes & Regularly & Often & Always & I don't know \\
\hline \multicolumn{6}{|c|}{ ometimes anticoagulation } \\
\hline Never & Sometimes & Regularly & Often & Always & I don't know \\
\hline \multicolumn{6}{|c|}{ ○ TAVI } \\
\hline
\end{tabular}

7. If the decision is between quality of life versus life expectancy with a certain prosthetic aortic valve, do you think that physicians can decide how these options should be weighed?

Never Sometimes Regularly Often Always I don't know

Case 1

Female, 30 years old. Aortic valve insufficiency, no comorbidity. Patient has a pregnancy wish.

$\begin{array}{lllllllll}\text { Mechanical valve } & 1 & 2 & 3 & 4 & 5 & 6 & 7 & \text { Bioprosthetic valve }\end{array}$

Case 2

Male, 64 years old. Aortic valve stenosis. Atrial fibrillation, patient is using acenocoumarol.

Mechanical valve $\begin{array}{llllllll}1 & 2 & 3 & 4 & 5 & 6 & 7 & \text { Bioprosthetic valve }\end{array}$

Case 3

Male, 50 years old. Aortic valve insufficiency. Cystic kidney disease and dialysis.

Mechanical valve $\quad \begin{array}{llllllll}1 & 2 & 3 & 4 & 5 & 6 & 7 & \text { Bioprosthetic valve }\end{array}$

Case 4

Male, 66 years old. Aortic valve stenosis. Hyperparathyroidism, coronary artery disease, impaired left ventricular function.

Mechanical valve $\begin{array}{llllllll}1 & 2 & 3 & 4 & 5 & 6 & 7 & \text { Bioprosthetic valve }\end{array}$

Case 5

Male, 65 years old. Aortic valve stenosis. No comorbidity.

Mechanical valve $\quad \begin{array}{llllllll}1 & 2 & 3 & 4 & 5 & 6 & 7 & \text { Bioprosthetic valve }\end{array}$

Case 6

Female, 70 years old. Aortic valve stenosis. No comorbidity.

Mechanical valve $\begin{array}{llllllll}1 & 2 & 3 & 4 & 5 & 6 & 7 & \text { Bioprosthetic valve }\end{array}$

Open Access This article is distributed under the terms of the Creative Commons Attribution License which permits any use, distribution, and reproduction in any medium, provided the original author(s) and the source are credited.

\section{References}

1. Tillquist MN, Maddox TM. Cardiac crossroads: deciding between mechanical or bioprosthetic heart valve replacement. Patient Prefer Adherence. 2011;5:91-9.

2. Vahanian A, Alfieri O, Andreotti F, et al. Guidelines on the management of valvular heart disease (version 2012): the Joint Task Force on the Management of Valvular Heart Disease of the European Society of
Cardiology (ESC) and the European Association for Cardio-Thoracic Surgery (EACTS). Eur J Cardiothorac Surg. 2012;42:S1-44.

3. Pibarot P, Dumesnil JG. Prosthetic heart valves: selection of the optimal prosthesis and long-term management. Circulation. 2009;119:1034-48.

4. Montori VM, Ting HH. Sharing decision-making about cardiac surgery. Circ Cardiovasc Qual Outcomes. 2009;2:519-21.

5. Elwyn G, Laitner S, Coulter A, et al. Implementing shared decisionmaking in the NHS. BMJ. 2010;341:c5146.

6. Elwyn G, Edwards A, Kinnersley P, et al. Shared decisionmaking and the concept of equipoise: the competences of involving patients in healthcare choices. $\mathrm{Br} \mathrm{J}$ Gen Pract. 2000;50:892-9.

7. Degner LF, Sloan JA, Venkatesh P. The control preferences scale. Can J Nurs Res. 1997;29:21-43.

8. Pieterse AH, Baas-Thijssen MC, Marijnen CA, et al. Clinician and cancer patient views on patient participation in treatment decision- 
making: a quantitative and qualitative exporation. $\mathrm{Br} \mathrm{J}$ Cancer. 2008;99:875-82.

9. Elwyn G, Frosch D, Rollnick S. Dual equipoise shared decisionmaking: definitions for decision and behaviour support interventions. Implement Sci. 2009;4:75.

10. Janz NK, Wren PA, Copeland LA, et al. Patient-physician concordance: preferences, perceptions, and factors influencing the breast cancer surgical decision. J Clin Oncol. 2004;22:3091-8.

11. Marshall DA, Johnson FR, Kulin NA, et al. How do physician assessments of patient preferences for colorectal cancer screening tests differ from actual preferences? A comparison in Canada and the United States using a stated-choice survey. Health Econ. 2009;18: $1420-39$.

12. Brothers TE, Cox MH, Robison JG, et al. Prospective decision analysis modeling indicates that clinical decisions in vascular surgery often fail to maximize patient expected utility. J Surg Res. 2004;120: 278-87.

13. Wilson IB, Green ML, Goldman L, et al. Is experience a good teacher? How interns and attending physicians understand patients' choices for end-of-life care. SUPPORT Investigators. Study to understand prognoses and preferences for outcomes and risks of treatment. Med Dec Making. 1997;17:217-27.

14. Cher D, Miyamoto J, Lenert L. Incorporating risk attitude into Markov-process decision models: importance for individual decision-making. Med Dec Making. 1997;17:340-50.
15. Sessums LL, Zembrzuska H, Jackson JL. Does this patient have medical decision-making capacity? JAMA. 2011;306:420-7.

16. Knops AM, Legemate DA, Goossens A, et al. Decision aids for patients facing a surgical treatment decision: a systematic review and meta-analysis. Ann Surg. 2013;257:860.

17. Manson NC. Why do patients want information if not to take part in decision-making? J Med Ethics. 2010;36:834-7.

18. van Til JA, Stiggelbout AM, IJzerman MJ. The effect of information on preferences stated in a choice-based conjoint analysis. Patient Educ Couns. 2009;74:264-71.

19. Hammermeister K, Sethi GK, Henderson WG, et al. Outcomes 15 years after valve replacement with a mechanical versus a bioprosthetic valve: final report of the Veterans Affairs randomized trial. J Am Coll Cardiol. 2000;36:1152-8.

20. Oxenham H, Bloomfield P, Wheatley DJ, et al. Twenty year comparison of a Bjork-Shiley mechanical heart valve with porcine bioprostheses. Heart. 2003;89:715-21.

21. Brennan JM, Edwards FH, Zhao Y, et al. Long-term safety and effectiveness of mechanical versus biologic aortic valve prostheses in older patients: results from the society of thoracic surgeons adult cardiac surgery national database. Circulation. 2013;127: $1647-55$.

22. Ruel M, Chan V, Bédard $\mathrm{P}$, et al. Very long-term survival implications of heart valve replacement with tissue versus mechanical prostheses in adults $<60$ years of age. Circulation. 2007;116(11 Suppl):I294-300. 